\section{¿Extensión? \\ ¿De qué estamos hablando?}

\section{Daniel Malano}

dmalano@unl.edu.ar

Sonia Sánchez

ssanchez@fca.unl.edu.ar
Docentes investigadores de la Universidad Nacional del Litoral,

Argentina.

Docentes de la Cátedra Electiva

de Extensión Universitaria.

Rubén Elz

relz@fca.unl.edu.ar

\section{Resumen}

En este artículo se abordan algunas cuestiones que surgen a lo largo de la práctica educativa de la cátedra de Extensión Universitaria en la Universidad Nacional del Litoral, y se propone el debate y reflexión respecto de los paradigmas educativos en el sistema universitario y las concepciones teóricas y académicas que se tiene de la extensión universitaria.

¿Qué y cuánto pasa inadvertido frente a nuestros ojos? Preguntas que iremos proponiendo y sustentado desde otros paradigmas científicos con la intención de no caer en simplificaciones ni definiciones sino, por el contrario, abriendo el abanico de la compleja realidad social con que se enfrenta la extensión.
Integración de la docencia y la extensión /

Perspectivas

RECEPCIÓN: 21/06/16

ACEPTACIÓN FINAL: 10/10/16

\section{Resumo}

Neste artigo se abordam algumas questões que surgem ao longo da prática educacional da disciplina de Extensão Universitária na Universidad Nacional del Litoral, e se propõe o debate e reflexão a respeito dos paradigmas eduacionais do sistema universitário e das concepções teóricas e acadêmicas que se tem da extensão universitária.

O que e quanto passa despercebido perante os nossos olhos? Perguntas que iremos propondo e sustentando desde outros paradigmas científicos com o intuito de não cair em simplificações nem definições, ao contrário, abrindo o leque da complexa realidade com que se defronta a extensão.

Palavras-chave

- Extensão universitária

- Paradigmas educacionais

- Complexidade
Para citación de este artículo

Malano, D.; Sánchez, S. y Elz, R. (2016). ¿Extensión? ¿De qué estamos hablando?. En Revista $+E$ versión digital, (6), pp. 36-41. Santa Fe, Argentina: Ediciones UNL. 


\author{
como docentes de una cátedra de extensión \\ universitaria, nos propusimos realizar una \\ acción desconcertante desde el punto de vista \\ tradicional: "desaprender".
}

\begin{abstract}
"Podría estar más tiempo analizando qué aprendí en tan pocos meses, y - podría decirse que algunas cosas hacen referencia a la extensión, pero muchas otras hacen referencia a la vida." (Luciano Andrés Favaretto, estudiante de la carrera de Medicina Veterinaria, 2015)
\end{abstract}

\section{Introducción}

Al sistema educativo lo transitamos como docentes, estudiamos, enseñamos, aprendemos, realizamos proyectos en el territorio, colaboramos con grupos para la concreción de sus proyectos, evaluamos y somos evaluados por el sistema universitario "convencional"1, imaginamos e implementamos estrategias educativas...

Quizás estas últimas sean para nosotros, como docentes de una cátedra de extensión universitaria, las más desafiantes, ya que nos propusimos realizar una acción desconcertante desde el punto de vista tradicional: "desaprender".

Desaprender no implica olvidar lo aprendido para aprender algo nuevo. Supone un pensamiento divergente que pueda poner en crisis tanto la certeza de que lo que supuestamente conocemos como verdad como los modos de hacer las cosas.

Siguiendo a Paulo Freire (1973) cuando se refiere a la educación y su rol:

"Lo que no podemos, como seres imaginativos y curiosos, es parar de aprender a buscar, de investigar la razón de ser de las cosas. No podemos existir sin interrogarnos sobre el mañana, sobre lo que vendrá, a favor de qué, contra qué, a favor de quién, contra quién vendrá, sin interrogarnos en torno de cómo hacer concreto el 'inédito viable' demandando de nosotros la lucha por él" (citado por Tommasino y otros, 2006:121).
1) Convencional: que reúne las características de lo que es habitual o tradicional. Ortodoxo.
De este modo, podríamos comenzar cuestionando aquello que se tiene establecido, los esquemas y formas de actuar de cada uno, de uno mismo. Desaprender implicaría afrontar y resolver los problemas de forma diferente a la habitual habiendo indagado en otros paradigmas científicos y del conocimiento, incluido el conocimiento y el saber cotidianos. Solo a través de la pregunta podremos poner en crisis nuestro conocimiento y veremos que aquello que llamamos "realidad" ya no es una única "cosa", ni es sólo exterior a cada uno, ni mucho menos imposible de cambiar. Es atinado en este momento recordar una frase atribuida a Albert Einstein que dice que "el universo no se puede cambiar, pero si cambias tú, tu universo cambiará".

A partir de lo dicho surgen preguntas que tienen que ver con puntos de partida. Esto es: ¿cómo mirar, observar, registrar el mundo que nos rodea, la realidad? ¿A través de qué paradigmas o con qué anteojos o desde qué matriz observamos, miramos, registramos ese mundo? Podemos ubicarnos desde la perspectiva de una mente que busca afuera —en el exterior, aquello que está allá- las causas de los efectos que se manifiestan en la vida, donde el observador no afecta lo observado. O hacerlo desde una mirada holística, multidimensional, integral y a la vez heterogénea, que comprenda que las causas de los efectos que se manifiestan en la vida externa están en la construcción interior, y que cada uno de nosotros es responsable de las decisiones que toma y que ellas tienen esos efectos visibles o perceptibles. Así, una mente que toma conciencia de que el mundo no es una realidad única e inequívoca pone en juego una multiplicidad de percepciones que conforman esa realidad.

Este paradigma no es novedoso, algunos fundamentos tienen más de dos siglos de comprobación, por ejemplo la experiencia vinculada al comportamiento de la luz. La experiencia de la "doble ranura" (Feynman, 1965) demuestra que el "efecto observador" es determinante para el comportamiento de los electrones, ya sea como partícula, ya sea como onda, y muestra de esta manera la dualidad en función de la intensión del observador. Otras nos llegan desde las investigaciones de Carl G. Jung (1970) y su teoría de "la 
sombra y los espejos", que está sustentada con las más recientes comprobaciones de las neurociencias respecto de la subjetividad de las percepciones sensoriales, los procesos neurofisiológicos y cómo el cerebro realiza las proyecciones y construcciones mentales. Estos planteos son los que subyacen a la noción de "desaprender". De allí que sea uno de los objetivos académicos centrales que intentamos promover en los espacios transversales de la extensión universitaria. Entendemos que es necesario desarticular los paradigmas que sustentan los campos disciplinares de las carreras para, posteriormente, lograr un cambio actitudinal que permita al estudiante tomar conciencia de su responsabilidad en la construcción de la realidad que observa.

Es así que partimos de un paradigma educativo diferente, considerando al "conocimiento" como inacabado e incompleto. De allí la necesidad de brindarle al estudiante las herramientas que le permitan "reconstruir" su propio conocimiento. Este nuevo aprendizaje disputa con una lógica que entiende al conocimiento acumulativo, que engrosa bibliotecas, que desecha unos que no son "oficialmente" dominantes ni habituales y enaltece otros como la única verdad posible.

Como el conocimiento no es un compartimento estanco, se requiere prestar suma atención a sus márgenes. Estar atentos a diversas teorías y prácticas de otras épocas, algunas que quedaron de lado u olvidadas por la ansiosa necesidad de implementar innovaciones en diversos órdenes. Bien sabemos que muchas de estas innovaciones responden a modas que poco cambian el trasfondo, sin reconocer que se establecen posiciones ideológicas, metodológicas y operativas. Construyen formas de pensar y actuar como las únicas válidas posibles, sin ponerlas en crisis.

Sabemos sobradamente que algunas teorías de autores se hacen visibles, son implementadas y opacan -e incluso invisibilizana otras.

¿Quién puede asegurar que lo "visible" es verdad, que es lo mejor, que es lo más útil y adecuado? ¿Cuánto es lo "invisible" qué se desconoce? ¿Qué y cuánto se nos pasa inadvertido frente a nuestros ojos? ¿Qué y cuántas oportunidades nos perdemos de conocer porque nuestros paradigmas (o creencias) nos lo impiden? $\mathrm{Si}$ "lo esencial es invisible a los ojos", ¿qué nos estaremos perdiendo, porque solo podemos observar una realidad, la propia?

\section{Extensión. ¿De qué estamos hablando?}

Antes de adentrarnos más en el tema de la extensión e intentar colapsar en una definición intelectual y académicamente correcta - cosa que no haremos para no poner un punto final que cierre el debate ineludible - se hace necesario que nos preguntemos: ¿de qué estamos hablando cuando decimos extensión?

En este punto de inicio, claro, no encontramos un único camino para transitar. Se nos aparece la frase de Antonio Machado ${ }^{2}$ una y otra vez: "Caminante no hay camino, se hace camino al andar". Sin embargo nos invade una percepción irreconciliable: todos los caminos son parciales, incompletos, subjetivos, que recortan en partes la realidad imposible de contener, en función de los modelos universitarios existentes. Bien podríamos convenir un camino, pero qué asegura que una convención será la más adecuada y compleja. Desde este momento nos queda claro que la extensión universitaria es abrir caminos y que no se sabe cuál es el punto de llegada. Quizás esto sea lo desconcertante de un posicionamiento epistemológico distinto.

¿Qué marcos, componentes, aspectos y dimensiones contiene y la contienen? ¿Existen límites que la puedan enmarcar o es su carácter difuso e inacabado, complejo, lo que la caracteriza? Si bien son necesarias las definiciones —la extensión no es una excepción que confirme la regla-, es importante reconocer que cuando algo se define se pierde mucho en el camino, hasta se pierdan muchos caminos. Definir es reconocer las intenciones que la orientan.

Entonces, ¿por qué la urgencia y la necesidad sistemática de definir a la extensión? ¿Será aquello tan importante en el ámbito universitario que la hace indefinible? No, ni es tan importante ni es tan indefinible, ya que todo se puede recortar y enmarcar y definir con el lenguaje. Si existe es porque el lenguaje le ha dado identidad.

Extensión, vista desde su concepción más simple: extender algo más allá de su posición original. ¿Es unilateral, es bilateral, es multilateral y dimensional, o es un proceso más complejo del que no se pueden visualizar sus alcances?

Ahora bien, frente a estas cuestiones que ya de por sí nos muestran un objeto complejo, nos preguntamos: ¿La extensión se puede enseñar en las aulas de las universidades? ¿Es éticamente válido 
enseñar preguntas, indefiniciones, complejidad, pensamiento holístico sin antes conceptualizar (o al menos esbozar un concepto)? ¿Qué es más importante, enseñar el concepto o posibilitar el proceso de conceptualización y apropiación de un saber? A esta altura podríamos suponer que si hiciéramos el ejercicio de cambiar el término "extensión" y poner en su lugar "educación" bien podría valer todo lo dicho anteriormente; y así nos adentramos aún más en la caverna. ¿O estaríamos saliendo de la caverna que Platón alegorizara?

Hemos nacido en la caverna. Estamos en la caverna. Sabemos que hay un afuera. ¿Habrá otra realidad? Pensemos mecánica y linealmente: ¿qué dimensiones habrá tenido la caverna de Platón? A ciencia cierta, no importa este dato, pero imaginemos y relacionemos por un instante la dimensión de la caverna y de la realidad que pudimos conocer en ella con el tamaño del resto del mundo. Solo pensemos en girar la cabeza y comprobar que lo que veíamos frente a nuestros inmóviles ojos no era la única realidad y que había algo más que lo proyectaba a su antojo y parecer. Luego pensemos que pudimos desamarrarnos y caminar hacia la salida de la caverna. Ahora visualicemos que llegamos a la puerta de la caverna y vemos un poco más allá. La última parte del juego sería imaginar que recorremos ese "más allá" que fue invisible e inexistente hasta esos momentos. ¿De qué modo analizaríamos esa nueva realidad? ¿Con qué parámetros la describiríamos y explicaríamos? ¿Con qué categorías podríamos hacerlo? ¿A partir de los conocimientos que nos fueron inculcados en la caverna? Siguiendo con esta alegoría, ¿se podría pensar a la universidad como una especie de caverna? Solo veamos de qué manera como habitual y mayoritariamente- se disponen los estudiantes en las aulas de clase. ¿Qué ha cambiado desde el año 347 a. C. desde que murió Platón? Dice Platón respecto de su alegoría en su libro República: "Y a continuación —seguí-, compara con la siguiente escena el estado en que, con respecto a la educación o falta de ella, se encuentra nuestra naturaleza" (1986: 514a). Dice Lucas José Villarreal, estudiante de la cátedra de Extensión de la carrera de Medicina Veterinaria: "Es difícil y amplio de explicar lo que aprendí” (Informe de evaluación 2015).

\section{Y... ¿dónde está la extensión?}

Como corolario, puesto que lo anterior determina una posición parcial y simplificada, la respuesta a esta pregunta podría ser tan obvia que hasta merecería no perder tiempo en responderla. Sin embargo, como somos miembros de una especie de caverna, lo diremos: "Dentro de la caverna no está", aunque ya de nada se puede estar seguro y afirmarlo a riesgo de equivocarse — nuevamente.
Si aceptáramos por un instante que la extensión no está en la caverna - ¿el aula?-, cabe la pregunta: ¿Qué estamos haciendo todos dentro del aula intentando "enseñar" extensión?

Jean Piaget sostenía que:

"la principal meta de la educación es crear hombres capaces de hacer cosas nuevas y no simplemente de repetir lo que han hecho otras generaciones; hombres creadores, inventores y descubridores. La segunda meta de la educación es formar mentes que puedan ser críticas, que puedan verificar y no aceptar todo lo que se les ofrece". (1981:78)

Ahora bien, esta frase resulta enunciativa y utópica cuando de "calidad educativa" se habla, ya que aunque es políticamente correcta no se condice con las habituales prácticas en la docencia universitaria que suele impartir los conocimientos acabados en igual medida para todos y que se evalúa del mismo modo, por cantidad de conocimientos devueltos (eruptados).

En la decisión de tomarnos seriamente esta función de la educación suponemos que si la universidad actual tiene solo la función de instruir no tendría sentido que exista, al menos como institución educativa. Pensamos en las normas y reglas (cuestiones de forma) para alcanzar un título universitario, con su curriculum formal - $\sin$ olvidar el "oculto" y menos aún el "currículo nulo" (o anulado)—, con la obligatoriedad de asistir físicamente, de escuchar, de leer, de retener, de memorizar, todo para luego reproducir el conocimiento de terceros impartido de segunda mano por otros terceros.

¿Quiénes no fuimos —o somos- parte activa y reprodujimos este modelo educativo dándole existencia y permanencia? ¿Cuántos aún hoy defendemos este modelo "reproductivo"? Pero, ¿cuántos intuimos que hay algo más allá de la caverna, aunque tememos enfrentarnos a lo desconocido?

Porque nuevamente "se hace camino al andar".

¿Podría ser la extensión aquello desconocido que aún permanece alejado y distante para la mayoría de los universitarios? Es tiempo de transformarnos nuevamente en pioneros del conocimiento que se atreven a explorar nuevos sitios y a dejar de lado el cómodo puesto de colonos que se asientan en territorios ya descubiertos, explorados y descritos por otros.

\section{Extensión. ¿Complejo... complicado? Educación: ¿simplificante... complejizante?}

"Muy cómodo. Se creó un ámbito de compañerismo, respeto, participación, compromiso mutuo y aprendizaje trilateral, tanto alumno-profesor como profesor-alumno y alumno-alumno". (Roberto "Tito" Kaenel, estudiante de la carrera de Medicina Veterinaria, 2015) 
Desde el planteo que estamos realizando, el tríptico que conforma nuestra pintura es extensión/educación/complejidad. En las diversas perspectivas educativas se nos aparecen los caminos que han hecho las distintas aproximaciones al hecho o fenómeno de la educación y su quehacer. La extensión se encuentra atravesada y a la vez solapada por dichas explicaciones. Sin embargo, algo podemos decir de ambas: que comprenderlas implica dar cabida a un acontecimiento, el de la complejidad. Pasaron varios años desde que abandonamos el camino "universitariamente correcto" por otro más "incorrecto" y no lineal: el de la imaginación y la intuición, donde la enseñanza y la demostración de saberes científicos tienen otro lugar, no ausentes sino corridos del lugar de privilegio habitualmente dado por la academia.

La creatividad también toma otro lugar, se la incentivará, se la liberará, se la respetará y se valorarán otros talentos en los estudiantes. Aquí es donde el pensamiento divergente comienza a cobrar sentido y permite que se pierdan los miedos a traspasar las barreras que habitualmente no se traspasan, no solamente por parte del alumnado sino también por parte de los docentes. El conocimiento académico es puesto en crisis y los saberes establecidos pasan a tener un plano de relatividad. Las creencias y certezas son puestas en juego para "jugar" con ellas.

Este proceso no es automático ni inmediato. No se trata de desestructurar por el hecho en sí mismo sino de fortalecer a los estudiantes en el encuentro con el otro. De revalorizar sus talentos, sus convicciones y sus conocimientos, de dar entidad a las emociones.

Por más que se lo proclame, este proceso se irá dando en la medida en que el docente baje sus barreras de poder y se sitúe en un plano más igualitario de intercambio y aprendizaje mutuo con la realidad. La confianza y el respeto deben ser los valores que permitan dar el salto cualitativo de una verdadera y compleja "integración" de la universidad con la sociedad de la cual es parte. Por otro lado, este cambio de paradigma de la docencia universitaria deberá estar respaldado por el cambio en aquellos momentos áulicos de encuentro con los estudiantes. No se podrá dejar de lado la asimilación de que el conocimiento universitario disciplinar y específico (por carreras, como es actualmente) pase por un proceso de "reintegración" interdisciplinar para que aquello que preconizara Jean Piaget sea una realidad.

\section{A modo de conclusión}

Tal vez parte de la clave nos la da Paulo Freire cuando dice: "Leer es un proceso abierto, y el verdadero maestro no es aquel que interpreta el texto de una manera y transmite esta única interpretación a sus alumnos; el verdadero maestro no es aquel que revela 'el sentido' del texto, sino aquel que sitúa a sus alumnos en el camino de la interrogación". (2013:13-14)

Un hecho anecdótico que suele ocurrir luego de realizar prácticas concretas en el territorio es el asombro que manifiestan muchos estudiantes al "descubrir" —redescubrir- el contraste entre el conocimiento teórico con la realidad concreta pero difusa y dinámica a la vez. Es como si su vida estudiantil no fuera más allá del hecho pasivo de ir clases, realizar las actividades prácticas encomendadas, estudiar y rendir los exámenes correspondientes. De este modo, a través del modelo de educación experiencial y autogestionaria implementado desde la cátedra Extensión Universitaria, la universidad deja de ser ese espacio concreto de reproducción y transferencia intelectual y formal para transformar lo institucionalizado en una vivencia única e irreproducible.

De las infinitas posibilidades que existen para cerrar un trabajo pretendidamente académico, seleccionamos un párrafo que sirva como reflexión final:

"Me gusta desarrollar mi conciencia para comprender por qué estoy vivo, qué es mi cuerpo y qué debo ser para cooperar con los designios del Universo. No me gusta la gente que acumula datos inútiles y se crea conductas postizas plagiadas de personalidades importantes. Me gusta respetar a los otros no por las desviaciones narcisistas de su personalidad sino por su desarrollo interno. No me gusta la gente cuya mente no sabe descansar en silencio, cuyo corazón critica a los otros sin cesar, cuyo sexo vive insatisfecho, cuyo cuerpo se intoxica sin saber agradecer estar vivo. Cada segundo de vida es un regalo sublime. (...) Me gusta colaborar y no competir. Me gusta descubrir en cada ser esa joya eterna que podríamos llamar dios interior. No me gusta el arte que diviniza el ombligo o quién lo practica. Me gusta el arte que sirve para sanar. No me gustan los tontos graves. Me gusta todo aquello que provoca la risa. Me gusta enfrentar voluntariamente mi sufrimiento con el objeto de expandir mi conciencia" (Jodorowsky) ${ }^{3}$. 


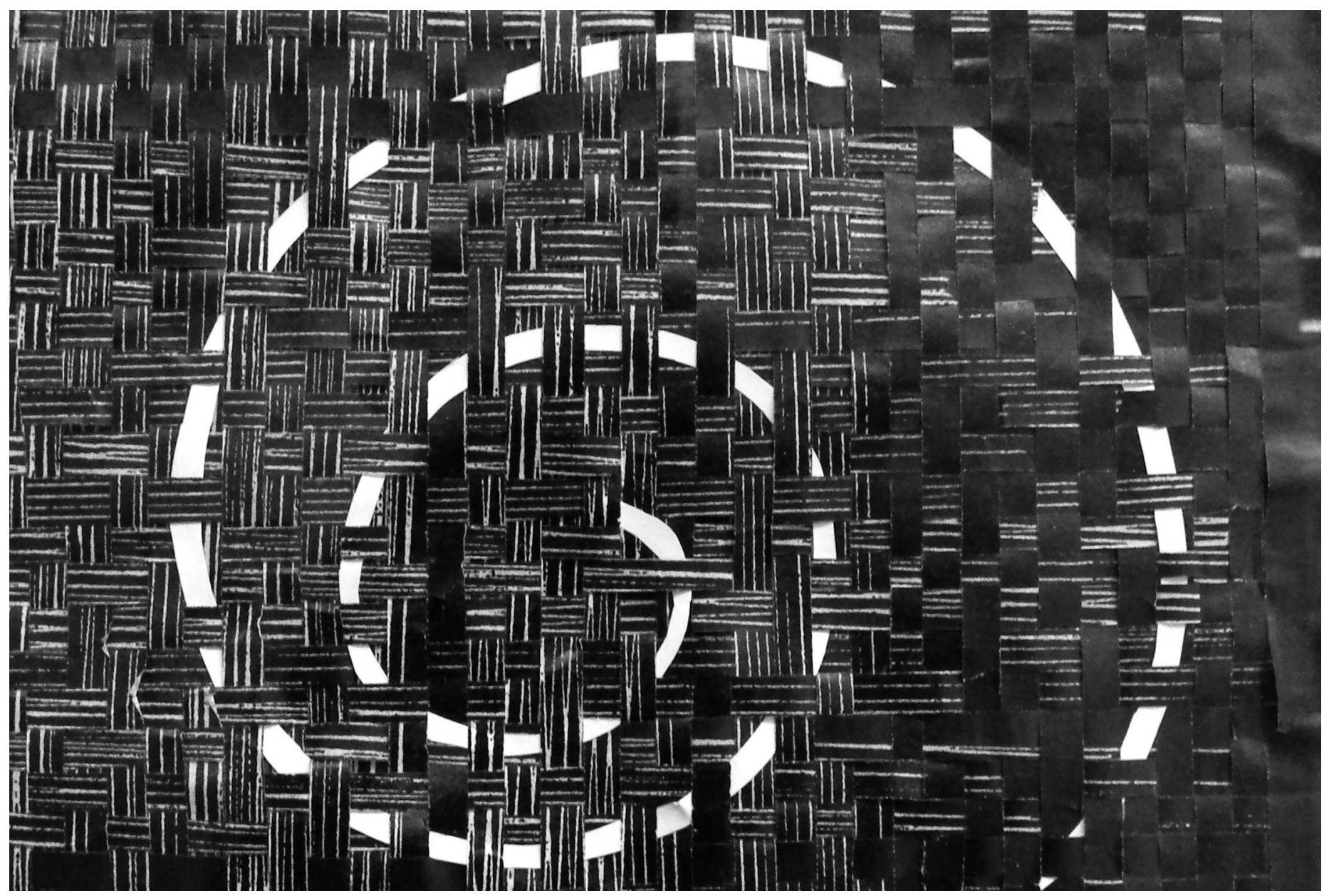

(C) Cecilia Iucci

\section{Referencias bibliográficas}

Feynman, R. (1965). The Character of Physical Law. Chapter 6. MIT.

Freire, P. (1973). ¿Extensión o comunicación? La concientización en el medio rural. Buenos Aires: Siglo Veintiuno Editores.

Freire, P. y Faundez, A. (2013). Por una pedagogía de la pregunta. Crítica a una educación basada en respuestas a preguntas inexistentes. Buenos Aires: Siglo Veintiuno Editores.

Jung, C. G. (1970). Arquetipos e inconsciente colectivo. Paidós.
Piaget, J. (1981). La teoría de Piaget, Infancia y aprendizaje. Barcelona: Gedisa. Platón (1966). República. Buenos Aires: EUDEBA.

Platón (1986). República. Libro VII, 514a-521d (Traducción de Eggers Lan, C.). Madrid: Gredos

Tommasino, $\mathrm{H}$ y otros (2006). Extensión: reflexiones para la intervención en el medio urbano y rural. Montevideo: Departamento de Publicaciones de la Facultad de Agronomía UdeLaR. 